\title{
NEW ECOLOGICAL COMPOSITES BASED ON NATURAL RENEWABLE RESOURCES
}

\author{
BEATA STRZEMIECKA, ŁUKASZ KLAPISZEWSKI, ARTUR JAMROZIK, \\ TEOFIL JESIONOWSKI \& ADAM VOELKEL \\ Poznan University of Technology, Faculty of Chemical Technology, Poznań, Poland.
}

\begin{abstract}
The use of the lignin-corundum hybrid fillers for phenolic resins was showed. The very important aspect of the use of lignin for phenolic resin composites is the reduction of phenol emission. The emission of phenol from the phenolic resin-hybrid filler composites were studied by headspace analysis. The physicochemical properties of the new hybrid fillers as well as the thermomechanical properties of the composites with them were examined. The surface properties of hybrid fillers were studied by inverse gas chromatography (IGC). The chemical structure of the new fillers was tested by Fourier transform infrared spectroscopy (FTIR). The dynamic mechanical thermal analysis (DMTA) was used to test the thermomechanical properties of the model composites for the use of abrasive tool production.

Keywords: headspace, kraft lignin-corundum hybrids, phenol emission, phenolic resins, rheological properties, surface characteristic, thermomechanical properties
\end{abstract}

\section{INTRODUCTION}

Recently, the renewable materials such as lignin, tannin are widely used as the ecological substitute of toxic phenol in phenolic resins. Lignin is one of the most common known biopolymer recently. The possibility of its utility in polymer composites is intensively studied [1-4]. Lignin is most often used as the phenols substitute in the phenolic resins due to the ecological and economical reason. Moreover, the phenolic resins can be partially replaced by lignin due to its similar chemical structure. It is known that lignin should be activated to enhance lignin/phenol-formaldehyde compatibility. Its reactivity to phenolic resin depends on e.g. the number of free phenolic hydroxyl groups and whether the ortho and para positions of its phenyl rings are blocked by methoxyl groups or aliphatic side chains [5-6].

Lignin acts a plasticizer [7-8]. Addition of lignin as a filler to polymer composites often worsens the mechanical properties [9]. In this work it is presented how to produce lignincorundum hybrids and used them as the fillers for phenolic resins composites to improve mechanical properties of the final composition and to decrease the emission of phenol into atmosphere.

In the literature there are some reports about association of lignin with clay [10]. Silicarecycled wood sawdust was described by Brostow et al. [11]. The polymer composites with such hybrids (silica-wood sawdust) showed better thermal stability, better compatibility with the polymer matrix and higher values of $E$ ' in DMA studies than composites with silica or wood sawdust used separately. Klapiszewski et al. have described an application of ligninsilica hybrids to polypropylene and have shown that addition of silica to lignin via this new hybrid formulation has a positive effect on the thermal stability of PP/silica-lignin composites [12]. In the literature, there are no reports of the application of corundum-lignin hybrids to polymer composites. Here, it was described the possibility of using such hybrid fillers for phenolic resins composites used in the abrasive articles industry. Moreover, there are not many reports on emission of the volatile compounds from polymer composites with natural renewable resources. Some results of the quantitative analysis of phenol emitted from the 
composition of lignin-corundum hybrids with phenol-formaldehyde resin are presented in this paper. The thermomechanical properties of the studied composites are also showed.

\section{EXPERIMENTAL}

\subsection{Material}

The novel, functional lignin-corundum hybrid materials were prepared by a mechanical method from corundum white micropowder (supplied by Imerys, Germany) and kraft lignin (Sigma-Aldrich, USA). Two lignin-corundum hybrids were studied with different lignin to corundum ratio: $1: 2$ and $2: 1$ by weight, respectively.

To combine corundum and lignin a mechanical process was used whereby the initial powders were ground and simultaneously mixed using a Pulverisette 6 Classic Line planetary ball mill (Fritsch, Germany). The three agate balls inside the vessel move due to the Coriolis force. To obtain suitably homogeneous final materials, grinding was continued for $6 \mathrm{~h}$. To prevent possible overheating of the material due to continuous grinding, every two hours the mill automatically switched off for $5 \mathrm{~min}$, after which it began operating again. After grinding the lignin-alumina hybrid materials were sifted using a sieve with a diameter of $40 \mu \mathrm{m}$.

For headspace analysis as well as thermomechanical one phenol-formaldehyde resins were used: novolac and resole supplied by Lerg ${ }^{\circledR}$, Pustków, Poland.

\subsection{FTIR analysis}

Samples of kraft lignin, corundum and new hybrid materials lignin-corundum were characterized by Fourier transform infrared (FTIR) spectroscopy, using a Vertex 70 spectrophotometer (Bruker, Germany). The materials were analyzed in the form of tablets, made by placing a mixture of anhydrous $\mathrm{KBr}(\mathrm{ca} .0 .25 \mathrm{~g}$ ) and $2.0 \mathrm{mg}$ of the tested material in a steel ring under a pressure of $10 \mathrm{MPa}$. The tests were performed at a resolution of $0.5 \mathrm{~cm}^{-1}$ in the range $4000-400 \mathrm{~cm}^{-1}$.

\subsection{IGC experiments}

Inverse Gas Chromatography (IGC) experiments were carried out using $30 \mathrm{~cm}$ long glass columns (I.D. $3 \mathrm{~mm}$ ) with the silanized inner walls. Temperature of the column was $30{ }^{\circ} \mathrm{C}$. Temperature of injector and detector was equal to $150{ }^{\circ} \mathrm{C}$. The column was conditioned at a given temperature by $2 \mathrm{~h}$. Dead-time was determined using methane as inert gas. The carrier gas was helium (flow-rate $15 \mathrm{~mL} / \mathrm{min}$ ). The following compounds were used as test solutes: hexane, heptane, octane, nonane, decane, dichloromethane, ethanol, ethyl acetate, 1,4-dioxane and acetonitrile.

\subsection{Headspace and GC conditions for the quantitative analysis of emitted phenol}

The following samples were put in the glass vials and sealed:

a) $0.93 \mathrm{~g}$ of resole $+0.21 \mathrm{~g}$ of novolac,

b) $0.93 \mathrm{~g}$ of resole $+0.21 \mathrm{~g}$ of novolac $+0.36 \mathrm{~g}$ lignin, 
c) $0.93 \mathrm{~g}$ of resole $+0.21 \mathrm{~g}$ of novolac $+0.36 \mathrm{~g}$ lignin-corundum hybrid (lignin:corundum $1: 2$ by weight),

d) $0.93 \mathrm{~g}$ of resole $+0.21 \mathrm{~g}$ of novolac $+0.36 \mathrm{~g}$ lignin-corundum hybrid (lignin:corundum 2:1 by weight).

The samples were heated in the thermostat at $180^{\circ} \mathrm{C}$ for $20 \mathrm{~min}$ (hardening temperature of phenolic resin bonded materials). The phase above the samples were passed through the sorption tube with the active carbon $(500 \mathrm{mg}$ ) by use of air pump. After sorption process the adsorbed phenol emitted from compositions (a)-(d) was desorbed by $50 \mathrm{~mL}$ of methanol. Then, the methanol with extracted phenol from active carbon was decanted. $1 \mathrm{~mL}$ of such sample were placed in the chromatographic vial and analyzed by Gas Chromatograph HP 5890 II (GC), Perlan Technologies Polska Sp. z o.o. (Poland).

Chromatograph was equipped with capillary column RestekRtx $5(30 \mathrm{~m} \times 0.25 \mathrm{~mm} \times 0.25$ $\mu \mathrm{m})$. Analysis was carried out using helium as carrier gas at a flow rate of $1.0 \mathrm{~mL} / \mathrm{min}$. The injector and detector temperature was $230^{\circ} \mathrm{C}$. The initial column temperature was $100{ }^{\circ} \mathrm{C}$, then ramped at $25^{\circ} \mathrm{C} / \mathrm{min}$ to $130^{\circ} \mathrm{C}$ and at $5{ }^{\circ} \mathrm{C} / \mathrm{min}$ to $150^{\circ} \mathrm{C}$. Total time of analysis was 6 min.

The whole procedure (from HS to GC analysis) was repeated five times. It should be stressed that the presented values of the phenol amount are right for comparison aim but they should not be treated as the absolute value of total amount of phenol emitted from the studied composites. The procedure of absolute calibration was applied and the calibration curve is presented in Fig. 1.

\subsection{Dynamic Mechanical Thermal Analysis}

The dynamic-mechanical properties of samples with dimensions of $10 \times 4 \times 50 \mathrm{~mm}$ were investigated by dynamic mechanical thermal analysis (DMTA) in torsion mode using an Anton Paar MCR 301 apparatus (USA) operating at frequency $\mathrm{f}=1 \mathrm{~Hz}$. The temperature

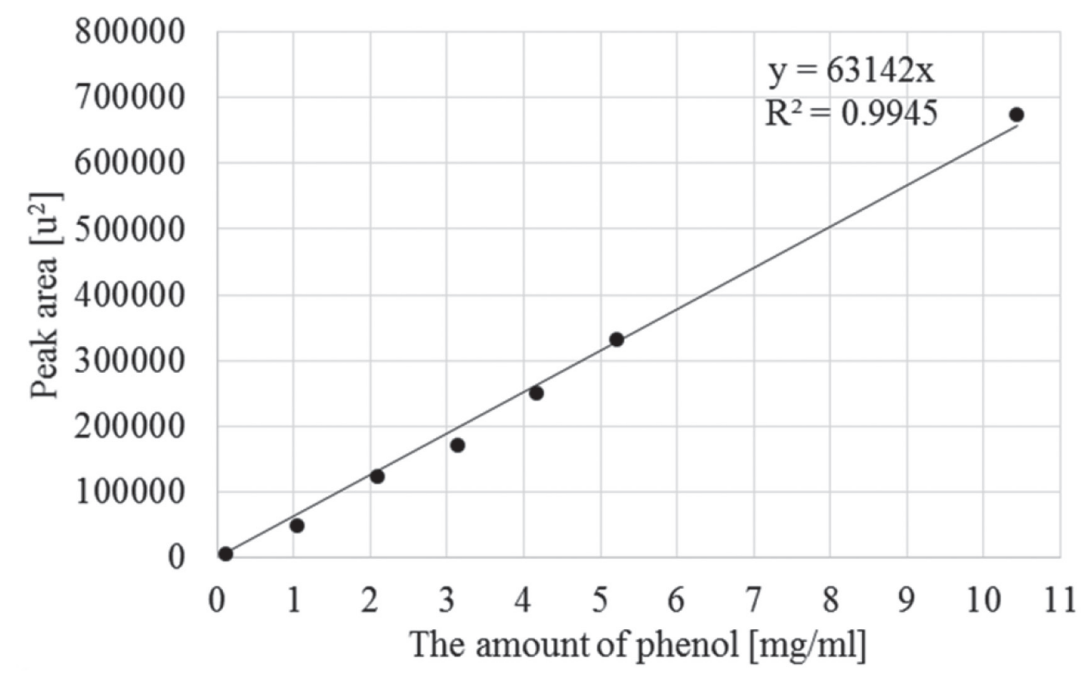

Figure 1: The calibration curve for the quantitative analysis of the phenol amount emitted from studied model phenolic resin-new hybrids composites. 
range was from 25 to $300^{\circ} \mathrm{C}$, with a heating rate of $2^{\circ} \mathrm{C} / \mathrm{min}$. The samples compositions were as follows:

a) novolac + resole + abrasive grains (fused alumina, Imerys, 120 mesh),

b) novolac + resole + abrasive grains (fused alumina, Imerys, 120 mesh) + lignin,

c) novolac + resole + abrasive grains (fused alumina, Imerys, 120 mesh) + lignin-corundum hybrids (1:2, wt./wt.),

d) novolac + resole + abrasive grains (fused alumina, Imerys, 120 mesh) + lignin-corundum hybrids $(2: 1$, wt./wt.).

\section{RESULTS AND DISCUSSION}

The FTIR spectra were performed to analyse chemical structure of lignin, corundum as well as the hybrids lignin-corundum and to prove the successful formation of these last ones. In Fig. 2, it can be seen that lignin-corundum hybrids represent all characteristic bands for lignin, especially the ones from aromatic ring $\left(1598,1508,1465 \mathrm{~cm}^{-1}\right)$ and from $\mathrm{C}-\mathrm{H}$ at $2940 \mathrm{~cm}^{-1}$. It is interesting that the bands $\mathrm{O}-\mathrm{H}$ groups in corundum (between 3700 and $2800 \mathrm{~cm}^{-1}$ ) disappeared in lignin-corundum hybrids. Moreover, the band of Al-O at $1400 \mathrm{~cm}^{-1}$ in corundum also disappeared in hybrid materials. It might suggest that lignin with corundum bonds via $\mathrm{O}-\mathrm{H}$ groups in corundum.

The surface interactions of filler and polymer matrix are crucial for their final properties. For this reason the surface of lignin, corundum and lignin-corundum hybrids were characterized by IGC technique. The dispersive and acid-base properties of the studied surfaces were assessed. The dispersive properties of the surface were described by use of the dispersive component of the surface energy, $\gamma_{s}^{d}$. The $\gamma_{s}^{d}$ was determined according to the Schultz-Lavielle method [13-16]. Acid-base properties of the surface were described by $K_{A}$ and $K_{D}$ parameters, respectively [14-16]. The IGC results are presented in Table 1.

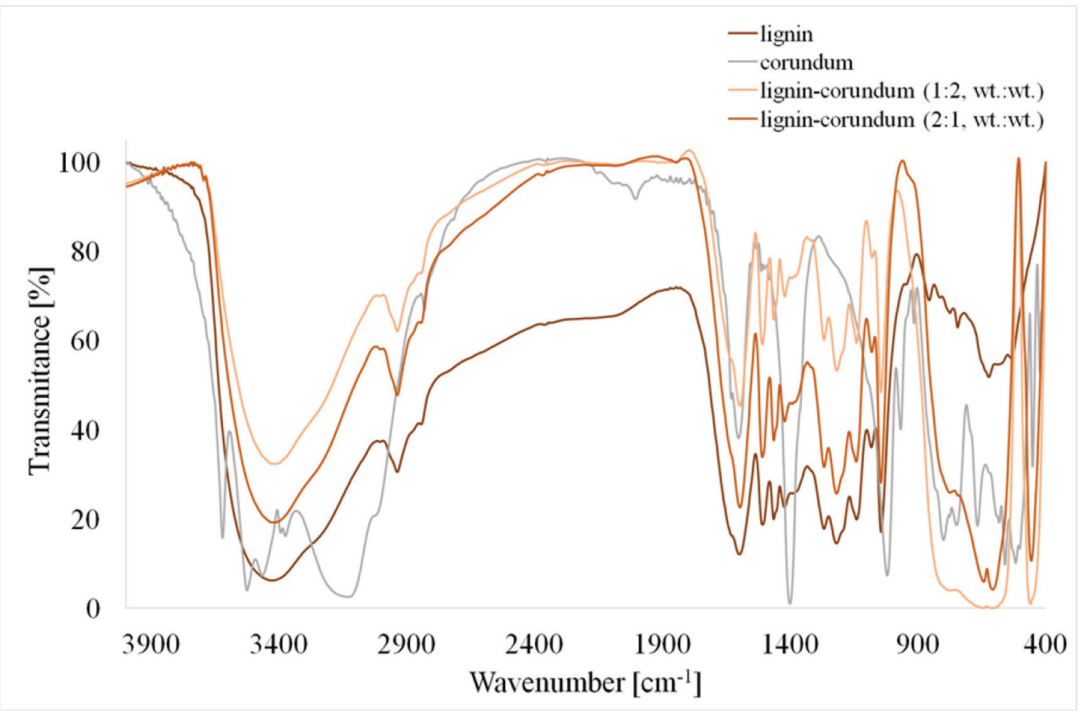

Figure 2: FTIR spectrum of kraft lignin, corundum and lignin-corundum hybrids. 
Table 1: The values of $\gamma_{s}^{d}, K_{A}$ and $K_{D}$ parameters estimated for corundum, lignin and lignincorundum hybrids by IGC.

\begin{tabular}{|c|c|c|c|c|}
\hline & & $K_{A}$ & $K_{D}$ & $K_{A} / K_{D}$ \\
\hline Sample & $\gamma_{s}^{d}\left[\mathrm{~mJ} / \mathrm{m}^{2}\right]$ & {$[-]$} & {$[-]$} & {$[-]$} \\
\hline corundum & $36.2 \pm 0.4$ & $0.098 \pm 0.010$ & $0.240 \pm 0.003$ & 0.408 \\
\hline lignin & $35.2 \pm 0.6$ & $0.112 \pm 0.005$ & $0.161 \pm 0.002$ & 0.696 \\
\hline lignin-corundum (1:2, wt./wt.) & $34.7 \pm 0.2$ & $0.090 \pm 0.003$ & $0.210 \pm 0.003$ & 0.429 \\
\hline lignin-corundum (2:1, wt./wt.) & $35.2 \pm 0.1$ & $0.099 \pm 0.001$ & $0.156 \pm 0.002$ & 0.635 \\
\hline
\end{tabular}

All studied materials are characterized by similar, medium surface activity as regards ability to the dispersive interactions: the value of the $\gamma_{s}^{d}$ for all samples is around $35 \mathrm{~mJ} / \mathrm{m}^{2}$. The values of $\gamma_{s}^{d}$ of alumina reported in Ref. [17-18] are higher than presented here. However, literature data were found for alumina of BET surface area about $10 \mathrm{~m}^{2} / \mathrm{g}$ [17] whereas corundum surface used in this work was below $1 \mathrm{~m}^{2} / \mathrm{g}$ ). The studied corundum surface acts as donor of electrons $\left(K_{D}>K_{A}\right)$. The donor character of the corundum can be the effect of the electron pair of oxide atoms on the corundum surface. The surface properties of alumina depend strongly on impurities level on the surface. The alumina surface contamination by even small amount of silica changed the surface of alumina into more acid [18]. Supplier statement and results of the preliminary studies of corundum by XPS show that there is no silica contamination on the surface of examined corundum. Lignin surface acts also as donor of electron $\left(K_{A} / K_{D}\right.$ equal to $\left.\sim 0.7\right)$. Basicity of lignin surface can be the effect of the presence of $-\mathrm{C}=\mathrm{O},-\mathrm{OCH}_{3},-\mathrm{OH}$ groups as well as electrons in aromatic rings. The most important difference between corundum and lignin as regards IGC parameters lies in the values of $K_{D}$. As expected, the surface of hybrid with higher content of lignin is more similar to lignin and, analogously, the surface of hybrid with higher content of corundum is more similar to corundum.

The very important point of these studies was that the quantitative analysis of the amount of phenol emitted from the composition of phenolic resins with lignin as well as lignincorundum hybrids. The amount of phenol emitted within 20 min of headspace analysis at $180^{\circ} \mathrm{C}$ from $1.14 \mathrm{~g}$ of phenolic resins with or without lignin fillers are presented in Table 2.

Table 2: The amount of emitted phenol from compositions as described in 2.4

\begin{tabular}{|c|c|c|}
\hline Sample & $\begin{array}{l}\text { The mass of emitted } \\
\text { phenol }[\mathrm{mg}]^{*}\end{array}$ & $\begin{array}{l}\% \text { of phenol in ratio } \\
\text { to the mass of resins }\end{array}$ \\
\hline Composition (a) (see 2.4) - without filler & $49.9 \pm 2.0$ & 4.4 \\
\hline Composition (b) (see 2.4) - with lignin & $35.4 \pm 0.6$ & 3.1 \\
\hline $\begin{array}{l}\text { Composition (c) (see } 2.4) \text { - with lignin- } \\
\text { corundum } 1: 2 \text {, wt./wt. }\end{array}$ & $33.9 \pm 1.5$ & 3.0 \\
\hline $\begin{array}{l}\text { Composition (d) (see } 2.4) \text { - with lignin- } \\
\text { corundum } 2: 1 \text {, wt./wt. }\end{array}$ & $34.9 \pm 0.5$ & 3.1 \\
\hline
\end{tabular}

${ }^{*}$ The mass of emitted phenol within 20 min at $180^{\circ} \mathrm{C}$, adsorbed on active carbon and desorbed with $50 \mathrm{~mL}$ of methanol 


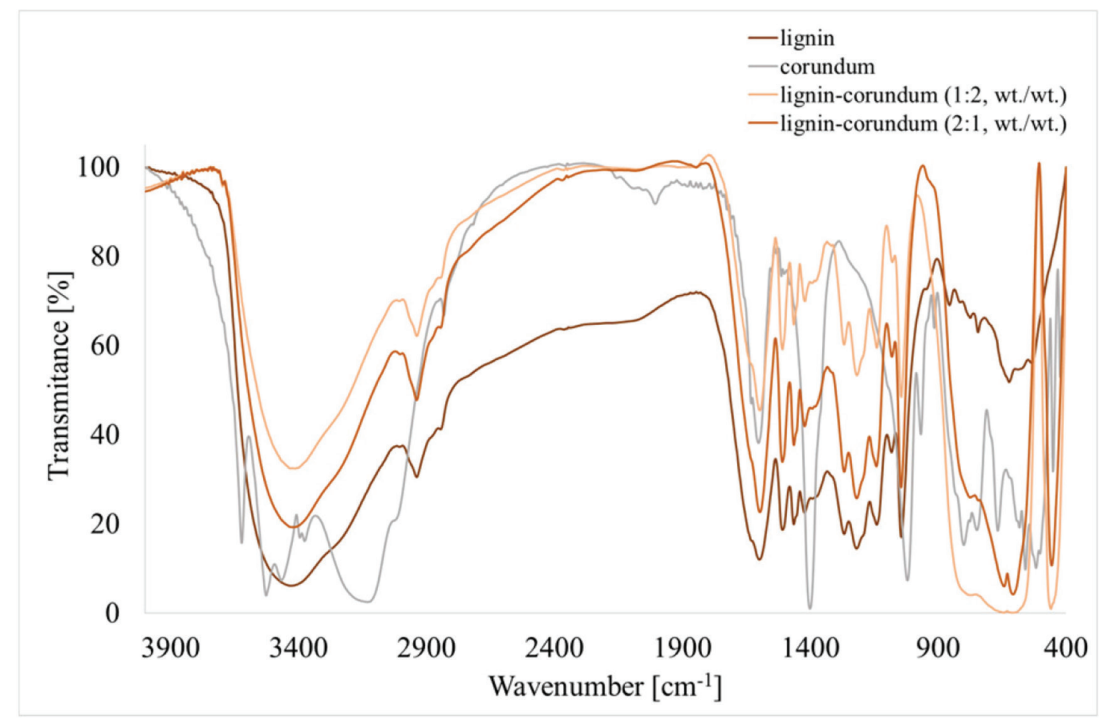

Figure 3: Storage modulus vs. temperature for compositions of kraft lignin, corundum and lignin-corundum hybrids.

The presence of lignin as well as lignin-corundum hybrids cause the decrease of the emission of phenol from phenolic resins during their heating at $180^{\circ} \mathrm{C}$ (Table 2). Thus, it might be concluded that in this conditions lignin is able to bond a portion of free phenol and in this way limits its emission to atmosphere. The decrease of phenol emission from resins in the presence of lignin and lignin-corundum hybrids is statistically significant but it is rather small. However, taking into account the amount of phenolic resins used in the different industry, e.g. abrasive articles, (kilograms per day) such reduction of phenol emission is meaningful.

It is also important how the presence of lignin and new hybrid fillers influence the thermomechanical properties of the final composition. The model abrasive article composition was studied (see section 2.5). DMTA analysis was performed. The storage modulus vs. temperature is presented in Fig. 3.

Lignin has the plasticizing effect ( $E^{\prime}$ decreased relative to the composition without resins). This can influence positively on the preparation of resin blends and their processing during the formation of final products. The lignin chains introduced into the matrix can increase the flexibility of the composites and may contribute to energy dissipation through internal friction [19]. The plasticizing effect of lignin-alumina fillers can decrease the fragility of composites. Usage of lignin-corundum fillers causes that the storage modulus decreased less during the thermal and mechanical load than in case of the composition with lignin and without fillers. Thus, the lignin-corundum hybrids might have stabilizing effect during the work of the final abrasive tool.

\section{CONCLUSIONS}

The new lignin-corundum hybrid materials can be the promising fillers, for example, abrasive industry. It was proved that the usage of such fillers can decrease emission of harmful phenol. Moreover, the final product with such fillers might possess the advantageous thermomechanical properties such as less fragile, more stable under the influence of temperature and 
mechanical load in comparison to phenolic resins themselves. To sum up, such fillers can be profitable new fillers for abrasive industry, especially taking into account economic and ecological aspects.

\section{ACKNOWLEDGEMENTS}

This work was supported by the National Science Centre Poland under research project no. DEC-2014/15/B/ST8/02321.

\section{REFERENCES}

[1] Comí, M., Lligadas, G., Ronda, J.C., Galià, M. \& Cádiz, V., Renewable benzoxazine monomers from "lignin-like" naturally occurring phenolic derivatives. Journal of Polymer Science Part A: Polymer Chemistry, 51, pp. 4894-4903, 2013. https://doi.org/10.1002/pola.26918

[2] Tejado, A., Kortaberria, G., Pena, C., Labidi, J., Echeverría, J.M. \& Mondragon, I., Lignins for phenol replacement in novolac-type phenolic formulations, part I: Lignophenolic resins synthesis and characterization. Journal of Applied Polymer Science, 106, pp. 2313-2319, 2007. https://doi.org/10.1002/app.26941

[3] Basso, M.C., Giovando, S., Pizzi, A., Celzard, A. \& Fierro, V., Tannin/furanic foams without blowing agents and formaldehyde. Industrial Crops and Products, 49, pp. 17-22, 2013.

https://doi.org/10.1016/j.indcrop.2013.04.043

[4] Li, X., Pizzi, A., Lacoste, C., Fierro, V. \& Celzard, A., Physical properties of tannin/ furanic resin foamed with different blowing agents. BioResources, 8, pp. 743-752, 2013.

https://doi.org/10.15376/biores.8.1.743-752

[5] El Mansouri, N.-E. \& Salvadó, J., Structural characterization of technical lignins for the production of adhesives: application to lignosulfonate, kraft, soda-anthraquinone, organosolv and ethanol process lignins. Industrial Crops and Products, 24, pp. 8-16, 2006.

https://doi.org/10.1016/j.indcrop.2005.10.002

[6] Hu, L., Pan, H., Zhou, Y. \& Zhang, M., Methods to improve lignin's reactivity as a phenol substitute and as replacement for other phenolic compounds: a brief review. BioResources, 6(3), pp. 3515-3525, 2011.

https://doi.org/10.15376/biores.6.3.3515-3525

[7] Strzemiecka, B., Klapiszewski, Ł., Jamrozik, A., Matykiewicz, D., Sterzyński, T., Voelkel, A. \& Jesionowski, T., Physicochemical characterization of functional ligninsilica hybrid fillers for potential application in abrasive tools. Materials, 9, pp. 517-530, 2016.

https://doi.org/10.3390/ma9070517

[8] Strzemiecka, B., Klapiszewski, Ł. Matykiewicz, D., Voelkel, A. \& Jesionowski, T., Functional lignin- $\mathrm{SiO}_{2}$ hybrids as potential fillers for phenolic binders. Journal of Adhesion Science and Technology, 30, pp. 1031-1048, 2016.

https://doi.org/10.1080/01694243.2015.1115602

[9] Yin, Q.F. \& Di, M.W., Preparation and mechanical properties of lignin/epoxy resin composites. Advanced Materials Research, 482-484, pp. 1959-1962, 2012.

https://doi.org/10.4028/www.scientific.net/amr.482-484.1959 
[10] Guigo, N., Vincent, L., Mija, A., Naegele, H. \& Sbirrazzuoli, N., Innovative green nanocomposites based on silicate clays/lignin/natural fibres. Composites Science and Technology, 69(11-12), pp. 1979-1984, 2009. https://doi.org/10.1016/j.compscitech.2009.05.001

[11] Brostow, W., Datashvili, T., Jiang, P. \& Miller, H., Recycled HDPE reinforced with sol-gel silica modified wood sawdust. European Polymer Journal, 76, pp. 28-39, 2016. https://doi.org/10.1016/j.eurpolymj.2016.01.015

[12] Klapiszewski, Ł., Bula, K., Sobczak, M. \& Jesionowski, T., Influence of processing conditions on the thermal stability and mechanical properties of $\mathrm{PP} /$ silica-lignin composites. International Journal of Polymer Science, 2016, pp. 1-12, 2016. https://doi.org/10.1155/2016/1627258

[13] Schultz, J., Lavielle, L. \& Martin, C., Proprietes de surface des fibres de carbone dèterminèes par chromatographie gazeuse inverse. Journal de Chimie Physique et de Physico-Chimie Biologique, 84, pp. 231-237, 1987. https://doi.org/10.1051/jcp/1987840231

[14] Voelkel, A., Strzemiecka, B., Adamska, K., Milczewska, K. \& Batko, K., Surface and bulk characteristics of polymers by means of inverse gas chromatography. In Polymeric Materials, ed. A. B. Nastasović \& S. M. Jovanović, Transworld Research Network: Kerala, pp. 71-102, 2009.

[15] Voelkel, A., Physicochemical measurements (Inverse Gas Chromatography). In Gas Chromatography, ed. C.F. Poole, Elsevier: Amsterdam, pp. 477-494, 2012.

[16] Voelkel, A., Strzemiecka, B., Adamska, K. \& Milczewska, K., Inverse gas chromatography as a source of physicochemical data. Journal of Chromatography A, 1216, pp. 1551-1566, 2009.

https://doi.org/10.1016/j.chroma.2008.10.096

[17] Papirer, E., Perrin, J.-M., Siffert, B. \& Philipponneau, G., Surface characteristics of aluminas in relation with polymer adsorption. Journal of Colloid and Interface Science, 144, pp. 263-270, 1991. https://doi.org/10.1016/0021-9797(91)90257-9

[18] Chehimi, M.M., Abel, M.-L., Watts, J.F. \& Digby, R.P., Surface chemical and thermodynamic properties of $\gamma$-glycidoxypropyltrimethoxysilane-treated alumina: an XPS and IGC study. Journal of Materials Chemistry, 11(2), pp. 533-543, 2001. https://doi.org/10.1039/b005227m

[19] Guigo, N., Mija, A., Vincent, L. \& Sbirrazzuoli, N., Eco-friendly composite resins based on renewable biomass resources: Polyfurfuryl alcohol/lignin thermosets. European Polymer Journal, 46, pp. 1016-1023, 2010.

https://doi.org/10.1016/j.eurpolymj.2010.02.010 